\title{
Pedagogia do cotidiano: reivindicações do currículo para a formação de professores
}

Rodrigo Saballa de Carvalho Paulo Sergio Fochi

\section{Resumo}

Com base nas contribuições da pedagogia da infância, discutem-se indicativos que possam estruturar a reflexão sobre a formação de professores para a educação infantil, tendo em vista a invenção e a operacionalização de uma pedagogia do cotidiano. Para tanto, metodologicamente, analisa-se um conjunto de relatórios de estágios curriculares, por meio dos quais se evidencia a maneira como as professoras em formação inicial consideram o cotidiano enquanto catalizador das experiências das crianças no que diz respeito à construção do currículo. Segundo as análises realizadas, conclui-se que a formação inicial de professores pode ser um potente modo de promover a construção de uma pedagogia do cotidiano que acolha as crianças com seus peculiares jeitos de ser, de viver e de habitar o mundo.

Palavras-chave: educação infantil; cotidiano; currículo; formação de professores; estágio supervisionado. 


\section{Abstract \\ Pedagogy of everyday life: demands of the curriculum for teacher training}

Based on contributions in the field of early childhood pedagogy, this paper aims to discuss markers capable of structuring thoughts about the teacher training for early childhood education, in view of the creation and operationalization of an everyday life pedagogy. To do so, methodologically, a set of compulsory internship reports is analyzed, disclosing the trainee teachers' view on the everyday life working as catalyst for children's experiences concerning the development of a curriculum. Thus, according to the analysis carried out, findings indicate that teacher training can be a powerful instrument to promote the development of an everyday life pedagogy that embraces all children in their particular ways of being, living and inhabiting the world.

Keywords: early childhood education; everyday life; curriculum; teacher training; supervised internship.

\section{Narrativas do cotidiano: notas de início}

Uma escola de educação infantil pode ser, apesar da acepção institucional da palavra escola, "uma pequena comunidade tanto para as crianças como para os adultos" (Galardini, 2017, p. 9). Apoiada por um clima de proximidade com as famílias e com a cultura em que está inserida, ela pode construir um sentido de acolhimento respeitoso das crianças dentro e fora de seu espaço institucional. Cumpre, com isso, sua função social, "que consiste em acolher, para educar e cuidar, [...] compartilhando com as famílias o processo de formação e constituição da criança pequena em sua integralidade" (Brasil. CNE, 2009b, p. 9).

A pedagogia de uma escola que acolhe aqueles recém-chegados ao mundo precisa ter como parâmetro seu papel de acompanhar os meninos e as meninas em seu crescimento e, por esse motivo, deve encontrar um modo de traduzir-se em práticas que se preocupem com o bem-estar e a autonomia das crianças (Galardini, 2017).

Os indícios encontrados na família das pedagogias participativas ${ }^{1}$ - que "produzem uma ruptura com uma pedagogia tradicional transmissiva para promover outra visão de ensino-aprendizagem e dos ofícios de aluno e professor" (OliveiraFormosinho; Formosinho, 2011, p. 15) - nos mostram que, no cotidiano das escolas, está a concretização do projeto educativo. Ou seja, é no modo como são pensados os tempos e espaços, como se dá a escolha dos materiais e a gestão do jogo social

\footnotetext{
${ }^{1}$ Nas pedagogias participativas, encontramos modelos curriculares (Oliveira-Formosinho, 2013), a exemplo de Reggio Emilia, High Scope, Pedagogia-em-Participação, Movimento da Escola Moderna (MEM), a abordagem de Emmi Pikler em Lóczy e de Elinor Goldschmied, entre outros.
} 
que a escola comunica suas crenças sobre o significado de educar crianças em espaços coletivos. Além disso, o cotidiano pode ser o catalizador da aprendizagem das crianças, pois, como afirma Staccioli (2017, p. 19), "se prestares atenção no que tens em frente a ti, no que sucede na cotidianidade, se te ocupas do que te rodeia, vais te dar conta de que o conhecimento depende de ti mesmo e, por isso, não tens necessidade de buscar nas coisas distantes, difíceis de perceber ou de compreender".

Partindo do pressuposto de que é preciso perceber a criança em sua inteireza, o cotidiano nos permite conciliar as "dimensões afetivas, as cognitivas, as relacionais e as psíquicas" (Staccioli, 2017, p. 19). Isso porque talvez seja no cotidiano que possamos aproximar os diálogos entre adultos e crianças (Carvalho; Fochi, 2016), rompendo os muros que separam a cultura da infância dos discursos pedagógicos. Também porque é inerente ao cotidiano a subversão da linearidade dos acontecimentos (Carvalho; Fochi, 2016) e, mais ainda, é nele que se alcança a difícil tarefa de equacionar a repetição e a abertura ao novo, ao emergente. Existe, nas atividades cotidianas, a continuidade de determinadas situações que, pela sua repetição, tanto nos asseguram criar intimidade e nos apropriarmos, como também nos dão "terra firme" para podermos vislumbrar o mundo que nos cerca. Ao mesmo tempo, são nelas que emergem acontecimentos imprevistos, abrindo-nos para alargar horizontes e afrontar o desconhecido.

O texto compartilhado aqui é decorrente de um esforço para refletir sobre a pedagogia da infância. Temos apostado na perspectiva de defender uma pedagogia do cotidiano, pois a entendemos "como uma unidade de inteireza da vida constituída por diversos fios - temporalidades, espacialidades, relações, linguagens - que se estabelecem na escola" (Carvalho; Fochi, 2016, p. 166). Em tal perspectiva, convém esclarecer que a pedagogia do cotidiano se sustenta nas contribuições teóricas do campo da pedagogia da infância, a qual consiste em um "conjunto de fundamentos e indicações de ação pedagógica que tem como referência as crianças e as múltiplas concepções de infância em diferentes espaços educacionais" (Barbosa, 2010, p. 14). Com base nas contribuições da pedagogia da infância relativas à importância da horizontalidade educativa entre adultos e crianças (Rocha; Lessa; Buss-Simão, 2016), da mediação entre as culturas infantis e as culturas mais amplas (Rocha; Lessa; Buss-Simão, 2016), da promoção da ação social das crianças (Barbosa, 2010), da valorização das múltiplas linguagens infantis e reconhecimento dos contextos de vida coletiva nos quais se situam as crianças dentro das instituições, cunhamos o conceito de pedagogia do/no cotidiano ${ }^{2}$ na educação infantil. Por essa razão, definimos a pedagogia do cotidiano como:

1) uma forma de entender que as crianças aprendem pela via da vida cotidiana, por meio "dos encontros, atividades, dificuldades e sucessos, a partir de um repertório de práticas" (Brougère, 2012, p. 17);

2) um modo de valorização e de promoção da miríade de experiências vivenciadas por meninos e meninas na vida diária da escola;

\footnotetext{
${ }^{2}$ Esclarecemos que se trata de uma pedagogia do/no cotidiano porque emerge das relações, indagações, investigações, proposições, mediações e descobertas que se realizam na vida diária das crianças na educação infantil.
} 
3) uma potente possibilidade de construir indicadores para a ação pedagógica na creche e na pré-escola que tomem como eixos norteadores do planejamento as interações, as brincadeiras e as maneiras peculiares como as crianças investigam, experimentam e constroem conhecimentos sobre si, sobre os outros e sobre o mundo;

4) uma "tradução" dos pressupostos teóricos da pedagogia da infância (Barbosa, 2010) em modos inteligíveis de atuação dos professores, atendendo à reivindicação realizada por Campos (2012).

Exposta a definição, convém fazermos um alerta. A pedagogia do cotidiano de forma alguma nega a "formação intelectual das crianças e a apropriação de outros saberes" (Rocha; Lessa; Buss-Simão, 2016, p. 46) advindos dos campos de experiências, mas se opõe incisivamente à antecipação do trabalho desenvolvido pelos anos iniciais do ensino fundamental na educação infantil. Afinal, contrapomonos à perspectiva educacional propedêutica defendida pelos economistas de que as crianças devem ser consideradas capital humano a ser investido desde a mais tenra idade (Carvalho, 2016).

Nesse sentido, afirmamos que, com base nas atividades da vida cotidiana, as crianças podem encontrar verdadeiros laboratórios: laboratório de cidadania, de participação e emancipação social, cultural e democrática; laboratório para aprender sobre a complexidade e os mistérios do mundo; laboratório da fantasia e da imaginação; laboratório estético e de experimentações diversas.

Para tal, este artigo está organizado em quatro partes. Na primeira, recuperamos a noção de currículo proposta pelas Diretrizes Curriculares Nacionais para a Educação Infantil (DCNEI) e, com sua utilização, mostramos como entendemos o lugar do cotidiano.

Na segunda parte, apresentamos o contexto de análise para a escrita do texto. Optamos por trabalhar com um conjunto de sete relatórios de estágio curricular em educação infantil, observando as reflexões produzidas por algumas alunas do curso de pedagogia. ${ }^{3}$ Desse modo, ressaltamos que a amostra dos relatórios de estágio que constituíram o corpus analítico do artigo foi definida segundo o critério de conveniência. Em outras palavras, foram selecionados relatórios que expressam aquelas experiências da prática do estágio curricular que se encontram em diálogo com a perspectiva por nós defendida de construção e operacionalização de uma pedagogia do cotidiano no contexto de vida coletiva da educação infantil.

Na terceira parte, expomos algumas categorias produzidas como consequência da análise dos relatórios de estágio, as quais podem servir como pistas para a construção de uma pedagogia do cotidiano. Por último, na quarta parte, apontamos a relação que acreditamos existir entre a pedagogia da formação dos professores que trabalham com crianças e a pedagogia das crianças, situando o cotidiano como chave dos dois âmbitos.

\footnotetext{
${ }^{3}$ Optamos por nomeá-las alunas, no feminino, pois há apenas a presença feminina no montante de relatórios de estágio escolhidos. Esses estágios foram supervisionados por Paulo Sérgio Fochi no âmbito do curso de pedagogia na Universidade do Vale do Rio dos Sinos (Unisinos) nos anos/semestres 2016/1, 2016/2, 2017/1.
} 


\section{Uma ideia de currículo em curso: o cotidiano em foco}

Currículo e cotidiano possuem uma relação imanente na educação infantil. Como lembram Brougère e Ulmann (2012), ocorrem, nas situações da vida cotidiana, aprendizagens que servem de vias de acesso para a compreensão dos funcionamentos sociais que são construídos e que constroem a relação das crianças com o mundo. Baseados em tal afirmação e inspirados nas proposições das DCNEI (Brasil. CNE, 2009b), defendemos o argumento de que as complexidades das atuações infantis somente serão acolhidas pelos professores se "as práticas do cotidiano forem tomadas como direção e sentido da ação pedagógica" (Carvalho; Fochi, 2016, p. 158) com as crianças. Nessa perspectiva, o currículo é entendido como "construção, articulação e produção de aprendizagens que acontecem no encontro entre as crianças e a cultura" (Brasil. MEC, 2009). Em suma, trata-se de um currículo que emerge da vida, dos percursos das crianças no mundo e que, portanto, é concebido

[...] como um conjunto de práticas que buscam articular as experiências e os saberes das crianças com os conhecimentos que fazem parte do patrimônio cultural, artístico, ambiental, científico e tecnológico, de modo a promover o desenvolvimento integral de crianças de 0 a 5 anos de idade. (Brasil. CNE, 2009b, art. $3^{\circ}$ ).

Cabe destacar que o conceito de currículo expresso nas DCNEI (Brasil. CNE, 2009b) não é baseado no conhecimento disciplinar escolar, pois é considerado um conjunto de práticas que possibilita aos professores elaborarem seus planejamentos com base nas experiências e nos interesses das crianças, tendo em vista as relações, as brincadeiras e a promoção das culturas infantis (Aquino; Vasconcellos, 2012). Ratificando o argumento, para Canavieira (2012, p. 43), o conceito de currículo expresso nas orientações curriculares possibilitou um "avanço na superação de algumas polêmicas dentro da área, como o peso do viés da psicologia cognitivista, o entendimento de formação de leitores e escritores na primeira infância e, principalmente, a importância das interações infantis no processo educativo".

Assim, podemos afirmar que o documento curricular defende a perspectiva pedagógica de que os processos de construção de conhecimentos pelas crianças pequenas nas instituições de educação infantil devem ocorrer por meio da participação efetiva delas nas práticas cotidianas. Nesse sentido, é ao protagonismo das crianças em suas pesquisas, experimentações, descobertas, invenções e teorizações, com base nas situações ordinárias vivenciadas no dia a dia da creche e da pré-escola, que se referem as diretrizes quando conferem centralidade ao cotidiano. Isso porque, na educação das crianças, o cotidiano potencializa a subversão de perspectivas educacionais lineares, promovendo a possibilidade de constituição e operacionalização "de uma pedagogia mais aberta aos acontecimentos extraordinários" (Carvalho; Fochi, 2016, p. 158).

Sob esse ponto de vista, o desafio proposto pelo documento curricular aos professores é articular as experiências e os saberes das crianças com os conhecimentos socialmente produzidos, diferenciando, desse modo, de forma radical, o currículo da educação infantil de uma visão propedêutica de escolarização precoce das crianças para as etapas subsequentes da educação básica. Essa afirmação demanda que os 
professores compreendam de fato e, sobretudo, valorizem os modos peculiares de as crianças conhecerem a si mesmas, aos outros e ao mundo, apoiadas em uma miríade de potentes linguagens com as quais elas interrogam a visão adultocêntrica que historicamente tem constituído as práticas de educação das crianças em nosso País. Isso significa que as diretrizes curriculares, além de reconhecerem as crianças como sujeitos históricos e de direitos, enfatizam que elas devem ser o centro do processo educativo; afinal, "não existem relações, conhecimento e aprendizagens que possam se desenvolver positivamente, senão em contextos acolhedores" (Fortunatti, 2016, p. 20). Ou seja, é preciso compreender que as crianças, com efeito, "atualizam seu potencial cognitivo e relacional quando convivem com adultos, com os quais compartilham espaços e tempos de experiência" potentes (Parrini, 2016, p. 75), nos quais é possível enxergar o extraordinário que reside nos acontecimentos ordinários da vida cotidiana.

Como professores e pesquisadores da área de educação infantil, apontamos que o investimento do trabalho pedagógico "não pode estar no ensino, mas concentrado na criação de contextos favoráveis para as diversas possibilidades de aprender" (Carvalho; Fochi, 2016, p. 158). Dessa maneira, "o ensino de conhecimentos sistematizados e tradicionalmente vinculados à lógica escolar não dá conta do universo complexo dos mundos da infância" (Brasil. MEC, 2009). Logo, com base nas orientações presentes nas diretrizes, é preciso que as instituições de educação infantil desenvolvam práticas pedagógicas que tenham, de fato, como eixos norteadores do currículo as interações e as brincadeiras.

Como consequência dos aspectos apresentados, cabe destacar as orientações presentes nas diretrizes curriculares a respeito das propostas pedagógicas das instituições de educação infantil, pois é por meio do planejamento de tais documentos que os professores podem efetivamente pensar em práticas que viabilizem que as "necessidades das crianças, os seus desejos, isto é, as suas vidas, entrem em sintonia com os saberes e conhecimentos" (Brasil. MEC, 2009, p. 51) historicamente construídos. Nesse sentido, as diretrizes defendem que as propostas pedagógicas da educação infantil devem considerar

\footnotetext{
[...] que a criança, centro do planejamento curricular, é sujeito histórico e de direitos que, nas interações, relações e práticas cotidianas que vivencia, constrói sua identidade pessoal e coletiva, brinca, imagina, fantasia, deseja, aprende, observa, experimenta, narra, questiona e constrói sentidos sobre a natureza e a sociedade, produzindo cultura. (Brasil. CNE, 2009b, art. $4^{\circ}$ ).
}

Após a leitura das proposições sobre os aspectos a serem considerados no planejamento das propostas pedagógicas, consideramos imprescindível ressaltar a necessidade de os professores possibilitarem condições, oportunidades e tempos para que as crianças possam vivenciar, de forma efetiva, uma experiência cotidiana de qualidade no contexto institucional. Ratificando o argumento, Parrini (2016, p. 75) afirma que o envolvimento ativo das crianças com os processos de aprendizagem, alicerçado no cotidiano, "é realizado somente quando os contextos em que elas habitam contemplam o estabelecimento de condições favoráveis e a realização de boas práticas firmemente orientadas para colocá-las no centro de suas experiências". 
Desse modo, defendemos que o cotidiano, em sua relação com o currículo, é um importante catalizador de experiências. Acreditamos que é a partir da potência do cotidiano (da vida emergente das relações ordinárias estabelecidas no contexto institucional) que podemos pensar no desenvolvimento de potentes ações pedagógicas que propiciem às crianças assumirem o papel de protagonistas na construção dos conhecimentos e de parceiros de jornada com os adultos professores.

\section{A formação inicial de professores de educação infantil: o estágio curricular docente como locus para encontrar pistas da pedagogia do cotidiano}

Na formação de professores, como afirmam Formosinho (2001) e OliveiraFormosinho (2005), estão envolvidas a experiência como alunos, a formação profissional (curso em nível de magistério ou superior) e, dentro dela, a prática pedagógica (estágio)

No ofício de aluno durante mais de uma década, aprende-se muito sobre ser professor, mesmo que de maneira implícita. Oliveira-Formosinho (2005, p. 4), ao referir-se às marcas que o ofício de aluno deixa nos futuros professores, alerta que "o posterior processo de formação profissional poderá desconstruir e reconstruir essas aprendizagens ou simplesmente estabilizá-las". Ocorre que, com os abstracionismos e generalismos da formação profissional dos cursos de pedagogia, resulta difícil descontruir os modelos de docência vividos na experiência como aluno e reconstruir novos modelos sobre o ser professor, em especial, sobre ser professor de crianças.

O modelo compartimentado de disciplinas e semestres que deixa ao aluno do curso de pedagogia a função de conectar tudo com todos, a inadequação com que se trata das crianças nas disciplinas pedagógicas, sobretudo das bem pequenas, e a ausência da pedagogia como campo de conhecimento do próprio curso de pedagogia (a qual continua, como afirma a história desse campo, subordinada a outros campos) em nada têm colaborado para que se reconstruam as aprendizagens relativas à docência.

A chegada dos estágios "serve para proporcionar ao futuro professor uma prática de desempenho docente global em contexto real que permita desenvolver as competências e atitudes necessárias para um desempenho consciente, responsável e eficaz" (Formosinho, 2001 apud Oliveira-Formosinho, 2005, p. 6).

No entanto, o estágio é, simultaneamente, uma janela que se abre para reconstruir os modelos de docência e um muro, pelos obstáculos que encontra: seja pela deficitária formação com que as alunas chegam ao estágio seja pelas más condições dos locais das práticas de estágio (as escolas de educação infantil).

Daí a escolha por buscar no estágio curricular as pistas possíveis para uma pedagogia do cotidiano, pois ele "constitui-se numa instância importante da relação entre a comunidade académica e a comunidade profissional" (Oliveira-Formosinho, 2005, p. 6) e desvela, na verdade, a emergência de um debate comprometido com 
a transformação dos contextos (Oliveira-Formosinho, 2016; Formosinho, 2001; Fochi, 2016) e sua vinculação com a própria formação dos adultos.

\section{O contexto dos estágios curriculares analisados}

Os relatórios de estágio curricular analisados foram produzidos no sétimo semestre do curso de pedagogia de uma universidade privada localizada na região metropolitana de Porto Alegre, como resultado dos processos da disciplina Estágio em Docência em Educação Infantil II. ${ }^{4}$ Antes dela, as alunas já devem ter frequentado as duas disciplinas específicas de educação infantil (Infância e Educação Infantil I e Infância e Educação Infantil II) e realizado o Estágio em Docência em Educação Infantil I, além de ter totalizado 100 créditos dos 168 do curso.

Além das disciplinas indicadas, as alunas já realizaram as demais disciplinas do curso, as quais tratam das diferentes interfaces entre as áreas do conhecimento (matemática, ciências, artes, educação física, etc.), a educação infantil e o ensino fundamental. No entanto, ainda é um tema que envolve a necessidade de uma série de avanços, pois, conforme relatos das alunas, nessas disciplinas, a educação infantil e, em especial, a das crianças menores de 3 anos de idade são pouco discutidas na relação com as diferentes áreas.

O estágio curricular é obrigatório e pré-requisito para a obtenção do título de licenciada em pedagogia. Nessa instituição, as alunas, enquanto mantêm encontros regulares semanais no período noturno com o professor supervisor do estágio, realizam 20 horas de observação e 150 horas de intervenção no período diurno na escola em que ocorrerá o estágio. Nesse conjunto de 170 horas, devem permanecer no mínimo 4 e no máximo 8 horas atuando com as crianças (primeiramente, na observação e, posteriormente, na atuação docente).

Por vezes, as alunas possuem um dia dedicado ao planejamento na escola, ou seja, não permanecem em atividades diretas com as crianças. Isso ocorre geralmente com aquelas que já trabalham como professoras titulares de turmas em escolas públicas (por possuírem o curso de magistério em nível médio). O município atende à Lei no 11.738 , de 16 de julho de 2008, que prevê um terço de sua carga horária voltada ao planejamento (hora-atividade). Nesses casos, optamos por manter, durante o período de estágio, a continuidade desse tempo para a realização das atividades de planejamento da ação pedagógica.

No caso das alunas que assumem turmas em escolas em que não atuam, e em que a professora titular também dispõe desse tempo, orientamos a escola a manter esse tempo para que a aluna estagiária possa dialogar com a professora de referência, a qual, em geral, permanece distanciada da turma durante o período de intervenção do estágio curricular.

As alunas que realizam seu estágio obrigatório em escolas em que atuam como monitoras (muitas vezes, em estágios remunerados não obrigatórios, na função

\footnotetext{
${ }^{4}$ Para facilitar a leitura, passaremos a utilizar apenas a expressão "estágio curricular".
} 
de auxiliar de sala) ou as alunas que atuam em escolas privadas (nas quais, com frequência, não existe tempo voltado para o planejamento durante o estágio obrigatório) não têm disponibilidade para esse tempo de planejamento dentro do horário da escola.

Na amostra de relatórios de estágios, os critérios estabelecidos para selecionálos envolveram: 1) a diversidade de contextos; e 2) as boas práticas.

Para boas práticas, adotamos a definição de "um esquema conceitual no qual pode se conectar e ordenar vários aspectos da vida educativa em relação a um princípio teleológico que assegure sua coerência e organicidade" (Bertin, 1973 apud Borgui, 2015, p. 21). Os critérios de validação para as boas práticas de estágio curricular analisadas abrangem, então, a coerência com as definições de criança e de currículo e os princípios éticos, estéticos e políticos postulados pelas atuais DCNEI (Brasil. CNE, 2009b) e pelo modo como as alunas - futuras professoras transformaram seu contexto de estágio com base em certa organização do cotidiano que traduz em práticas o respeito pelas crianças.

Com relação à diversidade de contextos, optamos por aqueles que nos parecem representativos da diversidade de realidades da educação infantil brasileira. Basicamente, no conjunto das sete experiências analisadas, encontramos:

- agrupamentos da creche;

- agrupamentos da pré-escola;

- instituições de educação infantil;

- instituição de ensino fundamental com turma de educação infantil;

- mantenedora pública;

- mantenedora privada;

- presença de apenas um adulto por agrupamento;

- presença de mais de um adulto por agrupamento;

- prédio de construção própria para a educação infantil;

- prédio adaptado;

- agrupamentos de crianças de pré-escola com mais de 20 crianças e de creche com 8 crianças por adulto (em turmas de 0-2 anos de idade) e 15 crianças por adulto (em turmas de 3 anos), conforme sugere o Parecer CNE/CEB nº 20, de 11 de novembro de 2009 (Brasil. CNE, 2009a).

No universo analisado, buscamos compreender como as intervenções realizadas pelas alunas de estágio curricular nos espaços, na reorganização do tempo e na escolha dos materiais ofertados promovem uma pedagogia que acolhe a participação das crianças e, como afirma Oliveira-Formosinho (2016), percebe-as como coconstrutoras de suas jornadas de aprendizagem. Como as alunas criaram um ambiente de escuta e acolhimento ao universo das crianças e o traduziram em documentação sobre elas e sobre seu próprio processo como professoras? De que modo a concepção de currículo e criança, os princípios éticos, estéticos e políticos apontados pelas DCNEI (Brasil. CNE, 2009b) se efetivaram nos contextos? 


\section{O contexto da supervisão de estágio}

Como já dito, nesse contexto das práticas pedagógicas na formação profissional, as alunas são acompanhadas por um supervisor de estágio. A supervisão na formação inicial, como aponta Oliveira-Formosinho (2005, p. 8), é radicalmente diferente da supervisão realizada dentro dos próprios contextos: "trata-se de orientar não professores, mas candidatos a professores, futuros professores, por definição, inexperientes, e em transição ecológica":

[...] desde a supervisão das práticas em nível da formação inicial, as educadoras precisam de conceptualizar a acção como ligada a conhecimentos, técnicas e destrezas que sustentam o profissionalismo da acção, mas também têm de referir essa acção aos valores e crenças inextricavelmente ligados aos conhecimentos, técnicas, destrezas. Têm igualmente de referir a acção aos valores e crenças da sociedade, isto é, à cultura envolvente que permeia, unifica, orienta, dá sentido histórico, social e cultural a todos os processos em torno do ensino-aprendizagem. (Oliveira-Formosinho, 2005, p. 13).

Por isso, é importante destacar que a escolha por esses estágios está ligada ao direcionamento dado às alunas nas supervisões. Ou seja, opta-se por sublinhar com as alunas a força do cotidiano para a construção de uma pedagogia da educação infantil.

No início, as alunas devem observar os locais em que farão a intervenção e, durante essa observação, recolher informações necessárias para produzir uma análise que identifique as pedagogias ali realizadas, para então planejar o modo como realizarão a intervenção.

De forma sumária, poderíamos dizer que a orientação envolve (Fochi, 2014): ${ }^{5}$

- o (re)planejamento da gestão do tempo, equilibrando os momentos optativos e os momentos conduzidos com as atividades de atenção pessoal e as demais atividades;

- a organização dos espaços em cantos de atividades diversificadas, garantindo a autoatividade das crianças, a descentralização do adulto, a diversidade de opções para que as crianças possam escolher o que fazer e a circunscrição de um lugar para que as crianças façam a própria gestão;

- a oferta de materiais não estruturados, diversificados, organizados de forma que as crianças possam acessá-los, apresentando cuidado e beleza no modo como são arrumados;

- a reflexão e o planejamento das transições dos diferentes momentos do cotidiano;

- a reflexão e o planejamento das atividades de atenção pessoal: comer, descansar e momentos de higiene;

- por fim, uma linha de investigação que se queira desenvolver ao longo da intervenção.

\footnotetext{
${ }^{5}$ Essas orientações compõem um documento que foi elaborado com as primeiras alunas de estágio curricular e serve de guia para a realização do estágio
} 
Tudo isso é o que temos chamado de planejamento de contexto (Fochi, 2015b, p. 5), no qual a ideia de planejamento "não está direcionada a um conjunto de aulas ou atividades e, tampouco, a propostas relacionadas às datas comemorativas. Planejar é fazer um esboço mais amplo sobre a gestão do tempo, sobre a organização dos espaços, sobre a oferta de materiais e sobre os arranjos dos grupos".

Após esse planejamento inicial, anterior à intervenção, as alunas iniciam seu planejamento semanal, o qual consiste em "saber propor para pequenos e grandes grupos sessões para articular os seus saberes com aqueles que a humanidade já sistematizou" (Fochi, 2015b, p. 7). Para esse planejamento, trabalhamos em três etapas inseparáveis: observar, registrar e interpretar para projetar (Fochi, 2015a, 2015b, 2016).

Nessa organização de planejamento, existem três momentos coincidentes. No primeiro, há a sistematização do contexto observado e refletido, a qual consiste em "organizar alguns dados que indiquem situações, narrativas ou aspectos observados nas crianças em suas interações no contexto educativo" (Fochi, 2015b, p. 8) - vale lembrar que partimos da ideia de um contexto já planejado. Desse modo, os aspectos elencados "passam a servir de mote para organizar algumas sessões para que as crianças vivam experiências intencionalmente planejadas, o que não significa que estejam fechadas" (Fochi, 2015b, p. 8). Por essa razão, ainda nesse primeiro momento, definem-se algumas hipóteses de aprofundamento e pesquisa, as quais são "questões relacionadas ao professor. Por exemplo, ele pode estar se perguntando que tipos de materiais propõem melhores zonas de aproximação e produções de narrativas para determinado grupo" (Fochi, 2015b, p. 8).

Com base no que foi sistematizado, as alunas passam, num segundo momento, a elaborar as condições de trabalho para criarem as sessões ao longo da semana, de maneira que explicitem como organizarão "o grupo e o tempo, quais materiais e espaços serão necessários e que instrumentos de registro e observação serão utilizados para gerar dados sobre os percursos das crianças e sobre a experiência educativa proposta" (Fochi, 2015b, p. 8).

Como consequência da experiência vivida ao longo da semana, no terceiro momento, as alunas registram a interpretação e valoração da semana: "partindo de fatos concretos referentes às ações das crianças, o adulto produz interpretações que poderão tornar-se, inclusive, mini-histórias" (Fochi, 2015b, p. 8). Por mini-histórias, compreendemos "rapsódias da vida cotidiana que, ao serem narradas textualmente e imageticamente, tornam-se especiais pelo olhar do adulto que as acolhe, as interpreta, e dá valor para a construção da memória pedagógica" (Fochi, 2016, p. 41).

Entre o planejamento de contexto, o planejamento das sessões e uma reflexão final envolvendo uma autoanálise das alunas sobre o que aprenderam em relação às crianças, à construção da docência e à produção do conhecimento ao longo do estágio constituem o que denominamos relatório de estágio, material utilizado para análise neste artigo. 


\section{Fragmentos do estágio docente em educação infantil: pistas de como apostar no cotidiano}

Tendo em vista a continuidade da discussão, retrataremos alguns aspectos extraídos de um conjunto de relatórios de estágios curriculares em educação infantil. Entendemos que tais relatórios, quando confrontados com o quadro teórico anteriormente exposto, mostram possibilidades para pensar no cotidiano como direção e sentido da pedagogia da infância (Carvalho; Fochi, 2016).

Optamos por apresentar transcrições de trechos que evidenciam as reflexões realizadas pelas estagiárias depois de suas intervenções. Isso porque, nessas intervenções, encontramos, com muita intensidade, o modo como elas observaram as ações das crianças e atribuíram sentido às relações entre currículo e cotidiano. Assim, como estratégia analítica, efetuamos uma leitura exploratória de sete relatórios, pela qual foi possível definir a pedagogia do cotidiano como eixo de discussão, bem como duas unidades de análise: 1) o cotidiano e a ecologia educativa; 2) o cotidiano e a participação das crianças. Apresentaremos a seguir cada uma das unidades e seus possíveis efeitos nos modos de pensar uma pedagogia do cotidiano da educação infantil.

\section{O cotidiano e a ecologia educativa}

Uma das pistas encontradas nos relatórios analisados diz respeito à procura das estagiárias para criar certa "ecologia educativa". Ou seja, trata-se de compreender o papel do adulto na transformação do clima de bem-estar e participação das crianças com base no planejamento do tempo, do espaço e dos materiais. O contraste do período de observação em que elas notavam e anotavam aspectos do funcionamento do grupo em que posteriormente realizariam estágio entrava em choque com o que estavam estudando e sendo orientadas na universidade. Também refletia marcas de suas próprias experiências como professoras.

Tomar consciência de seu papel diante da própria experiência educativa contribui significativamente para a construção de saberes pedagógicos (Contreras, 2010). No caso da docência na educação infantil, constitui aspecto-chave para a invenção desse tipo específico de ser professor.

\footnotetext{
Eu estava preocupada com o final da primeira semana. Fiquei pensando se tinha que fazer mais atividades dirigidas. Quando fiz a observação, as crianças não tinham tempo pra nada. Agora que organizei diferente o tempo, as crianças têm muito tempo para brincar. Elas me dizem que estão felizes. [...] Os espaços que organizei antes de iniciar o estágio estão fazendo uma diferença enorme. As crianças brincam em pequenos grupos. Às vezes fico perdida, pois não tenho o que fazer. Elas se resolvem sem mim. [...] Os materiais não estruturados são os preferidos das crianças. Elas fazem tantas coisas com aqueles materiais que fico pensando por que as escolas compram tanto brinquedo de plástico. Tudo mudou na escola quando mudei o modo de organizar o tempo, o espaço e os materiais. (E01) ${ }^{6}$
}

\footnotetext{
${ }^{6}$ Tendo em vista a manutenção do anonimato da identidade das participantes da pesquisa cujos relatórios estão sendo analisados, utilizamos, como convenção, a letra E (estágiária), seguida de um número (01-07) para diferenciar a autoria das transcrições. Além disso, ressaltamos que o uso dos relatórios como material de pesquisa foi autorizado pelas estagiárias, mediante a assinatura de um Termo de Consentimento Livre e Esclarecido.
} 
Já faz 8 anos que sou professora. Fiquei todo esse tempo tentando trazer "novidades" para as crianças para termos projetos para pesquisar. Me dei conta no estágio que o cotidiano diz tudo. As coisas para investigarmos com as crianças já estão ali, não precisa ficar pirando. O que temos que fazer é aprender a organizar o espaço, saber selecionar materiais interessantes e, o principal, dar tempo para as crianças brincarem. (E06)

À medida que as alunas foram reorganizando o ambiente educativo, começaram a perceber que a atuação das crianças se distanciava da forma como antes haviam observado. Nesse sentido, vão assumindo, de forma consciente, que as dimensões do espaço, do tempo e dos materiais impactam em profundidade a maneira como se vive o cotidiano. Sobretudo, impactam a descentralização do adulto, o que as convoca a procurar outros modos de ser e estar professoras de crianças.

No excerto abaixo, percebemos a busca não apenas para construir certa ecologia educativa, mas, sobretudo, para sustentá-la. Como se refere Hoyuelos (2015), existe na escola de educação infantil uma série de acontecimentos complexos que nos exige ter clareza em nossos princípios educativos para conseguir manter um projeto em marcha.

Hoje foi um dia difícil. Faltou uma professora na escola e ficamos com uma a menos. Na turma dos bebês isso faz muita diferença. [...] Como tínhamos organizado o esquema do adulto referência, se não tem um, precisamos ter um plano B. Minhas colegas me disseram que tínhamos que voltar a fazer como era antes [todos juntos ao mesmo tempo]. Eu disse pra elas que, enquanto estiver no estágio, vamos fazer tudo para garantir o bem-estar dos bebês. E isso é difícil, mas é o que precisamos fazer. (E04)

Ademais, a busca por essa ecologia educativa potencializa o cotidiano como um elemento horizontal do trabalho pedagógico, o qual, independentemente do que possa emergir em termos de projetos de aprendizagem ou propostas do professor, assegura um ritmo respeitoso com as crianças e com os adultos. Isto é, a ideia do cotidiano como uma ecologia educativa é a assunção das dimensões do cuidado e da pedagogia em harmonia, conforme elucidado nas narrativas:

Quando mudamos a organização do tempo, tudo mudou. Já se passam três semanas e, a cada dia, o que percebemos é que as crianças já notaram que têm tempo pra fazer tudo o que querem. [...] O momento de comer é o mais marcante. Organizar a mesa para o almoço com os amigos é incrível. As crianças contam em casa como os colegas arrumaram a mesa. Os pais estão nos dizendo que as crianças querem fazer em casa também. [...] Quando olho para o que fazíamos antes do estágio, eu me dou conta que o tempo [referindo-se ao modo como na escola organizam o tempo] é o maior problema. Organizamos sem pensar nas crianças. (E02; E03)

Tem dois bebês que ainda não estão adaptados. Já faz quatro semanas que estou fazendo o estágio e percebo que eles não estão bem. [na semana seguinte] Depois da conversa com o supervisor, comecei a ficar mais próxima deles e pedi para a mãe deles demorarem um pouco mais quando saem da escola. Percebi que eles precisavam se sentir confiantes comigo. [...] A ideia de ter algo de casa, com o cheiro de casa, parece milagre. Acalma eles. Um deles, percebo que essa semana está muito melhor. O outro ainda tem uns momentos de choro intenso, mas já consegue ficar mais tranquilo por mais tempo. (E07)

Nota-se que é preciso desenvolver uma observação e uma escuta sensíveis para potencializar uma pedagogia do cotidiano na educação infantil, pois "os 
processos de aprendizagens das crianças são racionais, sensoriais, práticos, emocionais e sociais ao mesmo tempo, isto é, envolvem todas as dimensões da vida - a emoção, a cognição e a corporeidade" (Barbosa; Horn, 2008, p. 26). Por essa razão, enfatizamos que as transcrições dos relatórios abordam o modo como as estagiárias enfrentaram o desafio de pensar uma ecologia educativa com base no cotidiano vivenciado por elas e pelas crianças em sua jornada diária. Nesse sentido, tempo, espaço e materiais não são vistos de modo estanque pelas estagiárias, mas como aspectos culturais e pedagógicos indissociáveis, por meio dos quais é possível potencializar a vida que pulsa todos os dias na escola da infância.

Como lembra Fortunatti (2016, p. 20), o trabalho do professor "deve começar a partir do investimento na organização de um quadro de oportunidades capaz de gerar experiências". Isso implica afirmar que "a qualidade da experiência das crianças na escola está relacionada com a qualidade das características que constituem o contexto educativo" (Parrini, 2016, p. 75). Em outras palavras, é no cotidiano que residem as pistas para que possamos pensar em práticas que tornem as crianças protagonistas de suas ações, descobertas e construção de saberes.

\section{O cotidiano e a participação das crianças}

Outro elemento encontrado nos relatórios das alunas diz respeito à abertura para a participação das crianças no cotidiano pedagógico. À medida que vão compreendendo o modo de atuar com as crianças e, inclusive, que a organização do tempo, do espaço e dos materiais afeta de forma direta as relações e interações, as alunas percebem outras possibilidades de as crianças estarem engajadas nas decisões e no jogo social da escola. Tal argumento é evidenciado na transcrição a seguir.

\footnotetext{
Começamos as manhãs com as assembleias já faz duas semanas. A de hoje foi incrível. As crianças sugeriram coisas para a reorganização do espaço, reclamaram que ontem tiveram pouco tempo pra brincar e me pediram para fazer um projeto sobre a escrita das cavernas. Acho que a história que li ontem fez com que se interessassem por isso. (E06)
}

Acolher a "reclamação" das crianças é uma pista que nos impressionou na leitura dos relatórios. Esse outro lugar que as crianças vão ocupando na relação educativa em que o adulto as escuta e toma esses aspectos como parte de suas reflexões pedagógicas nos mostra como, no cotidiano educativo, podemos ascender de uma pedagogia transmissiva para uma pedagogia participativa. Nessa transição, estamos mudando radicalmente nossa visão de homem, de aprendizagem, do papel da escola e da dimensão cívica do ato educativo.

Pensar em estratégias para que as crianças possam fazer parte, pertencer e participar da vida cotidiana é uma das dimensões do papel do adulto na educação infantil. Ao mesmo tempo, esse reposicionamento do adulto lhe oferece a oportunidade para que ocupe outro lugar, de quem observa para aprender sobre as crianças, sobre o modo como aprendem e constroem o conhecimento e, do mesmo modo, sobre seu papel. Esse outro lugar, de um adulto que intervém menos, que 
cria estratégias para que as crianças atuem, não é um caminho fácil; ao contrário, é um forte desafio para concretizar diferentes modos de estar com as crianças em instituições de educação infantil.

\begin{abstract}
Como as crianças estão envolvidas com a comida, nós tivemos que descobrir outro lugar para nós como professoras. Acho que essa é a parte mais difícil. Aprendemos a ser professoras fazendo tudo. Quando as crianças também estão fazendo as coisas do dia a dia, nós precisamos encontrar outro modo de ajudar elas. (E02)
\end{abstract}

Encontrar, nos relatórios, a disponibilidade da escuta é, ao mesmo tempo, um sinal do modo como o dia a dia da escola está funcionando e permitindo relações mais próximas e respeitosas e o motor para que as alunas percebam o lugar das crianças na centralidade do planejamento educativo (Brasil. CNE, 2009b). Esse aspecto é enfatizado no relato:

Uma criança me disse hoje: "Profe, esse espaço das fantasias não está funcionando. Vamos tirar e transformar num posto de gasolina". Eu já tinha dito para o supervisor que achava que esse era o canto que as crianças menos brincavam, e ele sugeriu que eu prestasse atenção no que elas estavam precisando. As crianças me salvaram. Agora transformamos o canto das fantasias em um posto de gasolina, e o pai de uma das crianças nos doou muitas coisas do posto que ele trabalha. [Duas semanas depois] As crianças sugeriram nessa semana que o pai do Lucas viesse na escola falar sobre como é trabalhar no posto. Fizemos o convite, e hoje ele veio falar com as crianças. Ele estava tão nervoso. Mas foi muito legal. O Lucas nunca se sentiu tão especial como hoje. Isso foi importante pra relação dele com as outras crianças. Acho que vamos ter algumas investigações pra fazer sobre o posto de gasolina. Que pena que meu estágio termina na próxima semana! (E05)

A participação das crianças é a palavra-chave nos trechos dos relatórios apresentados. As estagiárias evidenciam, em seus escritos, a imagem de uma criança potente, a imagem de seres humanos relacionais, capazes de expressar opiniões e sugerir mudanças nas propostas, ocupando um espaço efetivo nos processos de decisão do que ocorre (ou pode ocorrer) no contexto educativo. Dessa maneira, como as estagiárias, defendemos que "a criança emerge como coconstrutora, desde o início da vida, do conhecimento, da cultura, da sua própria identidade" (Dahlberg; Moss; Pence, 2003, p. 72); mas, para tanto, é preciso que os professores possibilitem espaços para sua participação. Isso porque, tal como Dahlberg, Moss e Pence (2003), acreditamos que a criança pequena é um sujeito único, complexo, individual, forte e poderoso. Assim, "os argumentos apresentados implicam necessariamente que se pense na continuidade das experiências lúdicas no cotidiano tendo em vista a potencialização de tempos, espaços e materiais" (Carvalho; Radomski, 2017, p. 47), para que as crianças, por meio de uma participação efetiva, possam produzir significados para suas descobertas.

\title{
Considerações finais: quando o cotidiano é o catalizador das aprendizagens
}

Atualmente, de acordo com Oliveira-Formosinho (2007, p. 13), vivenciamos "uma quase esquizofrenia educativa em que se naturalizou a distância entre as 
propostas e a realidade pedagógica experienciada por adultos e crianças". Notamos que essa esquizofrenia tem se efetivado em nosso País, a partir da tentativa de, cada vez mais cedo, escolarizar as crianças, objetivando sua preparação para os anos iniciais do ensino fundamental. Contrários à perspectiva de escolarização das crianças e assumindo as indicações das DCNEI (Brasil. CNE, 2009b), entendemos que os professores devem estar atentos aos modos como as crianças pequenas se relacionam com o mundo e à especificidade dos recursos que utilizam, como a corporeidade, a linguagem e a emoção na vida que transcorre no cotidiano da escola.

Consideramos imprescindível possibilitar às crianças experiências que possam ser exploradas por um corpo que sente e pensa desde o nascimento. Por essa razão, defendemos que a construção do conhecimento na educação infantil "se efetiva nas práticas cotidianas, nas experiências de socialização e no acesso a patrimônios já sistematizados pela humanidade, pois, assim como na visão da criança, o conhecimento não é fragmentado" (Carvalho; Fochi, 2016, p. 157) e, sim, sempre construído por meio de uma relação dialógica entre o homem e o mundo. Corroborando o argumento, Rinaldi (2012, p. 30) afirma que "as aprendizagens das crianças não ocorrem de forma linear, determinadas em estágios progressivos e previsíveis, mas, pelo contrário, são construídas por meio de avanços simultâneos, paralisações e 'recuos' que tomam diversas direções". A aprendizagem não acontece por transmissão ou reprodução. É um processo no qual cada criança constrói para si mesma as razões, os "porquês", os significados das coisas, dos outros, da natureza, dos acontecimentos, da realidade e da vida.

Pelos motivos expostos, entendemos que é necessário possibilitarmos experiências que sejam decorrentes de elaborações, mobilizem diretamente as crianças, deixem marcas e possam ser recuperadas na vivência de outras situações semelhantes, constituindo um aprendizado em constante movimento. Isso porque, conforme Carvalho e Radomski (2017, p. 55), "o aprender pela vida cotidiana é central na ação pedagógica desenvolvida na educação infantil". É mediante o "reconhecimento do aprendizado pela vida cotidiana que é possível declarar o papel social e político da escola como contexto de vida coletiva" (Carvalho; Radomski, 2017, p. 55). Eis o desafio.

\section{Referências bibliográficas}

AQUINO, L. M. L.; VASCONCELLOS, V. M. Questões curriculares para educação infantil e PNE. In: FARIA, A. L. G.; AQUINO, L. M. L. Educação infantil e PNE: questões e tensões para o século XXI. Campinas: Autores Associados, 2012. p. 69-82.

BARBOSA, M. C. S. Pedagogia da infância. In: OliveIRA, D. A.; DUARTE, A. C.; VIEIRA, L. F. Dicionário: trabalho, profissão e condição docente. Belo Horizonte: UFMG/Faculdade de Educação, 2010. p. 10-14.

BARBOSA, M. C. S.; HORN, M. G. Projetos pedagógicos na educação infantil. Porto Alegre: Artmed, 2008. 
BORGUI, B. Q. Educar en el 0-3: la práctica reflexiva en los nidi d'infanzia. Barcelona: Graó, 2015.

BRASIL. Lei no 11.738, de 16 de julho de 2008. Regulamenta a alínea "e" do inciso III do caput do art. 60 do Ato das Disposições Constitucionais Transitórias para instituir o piso salarial profissional nacional para os profissionais do magistério da educação básica. Diário Oficial da União, Brasília, 17 jul. 2008. Seção 1, p. 1.

BRASIL. Ministério da Educação (MEC). Secretaria de Educação Básica (SEB). Práticas cotidianas na educação infantil: bases para a reflexão sobre as orientações curriculares. Brasília: MEC/SEB; UFRGS, 2009. Projeto de cooperação técnica MEC e UFRGS para construção de orientações curriculares para a educação infantil; consultora Maria Carmen Silveira Barbosa. Disponível em: $<$ http://portal.mec.gov.br/index.php?option $=$ com_contentGview $=$ articleGid $=134$ 53GItemi>. Acesso em: 6 nov. 2017.

BRASIL. Conselho Nacional de Educação (CNE). Câmara de Educação Básica (CEB). Parecer CNE/CEB n 20, de 11 de novembro de 2009. Revisão das Diretrizes Curriculares Nacionais para a Educação Infantil. Diário Oficial da União, Brasília, 9 dez. 2009a. Seção 1, p. 14.

BRASIL. Conselho Nacional de Educação (CNE). Câmara de Educação Básica (CEB). Resolução no 5, de 17 de setembro de 2009. Fixa as Diretrizes Curriculares Nacionais para a Educação Infantil. Diário Oficial da União, Brasília, 18 dez. 2009b. Seção 1, p. 18.

BROUGÈRE, G. Vida cotidiana e aprendizagens. In: BROUGÈRE, G.; ULMANN, A. L. (Org.). Aprender pela vida cotidiana. Campinas: Autores Associados, 2012. p. $11-23$.

BROUGÈRE, G.; ULMANN, A. L. Sair da sombra: as aprendizagens cotidianas. In: BROUGÈRE, G.; ULMANN, A. L. (Org.). Aprender pela vida cotidiana. Campinas: Autores Associados, 2012. p. 1-6.

CAMPOS, M. M. Infância como construção social: contribuições do campo. In: VAZ, A. F.; MOMM, C. M. (Org.). Educação infantil e sociedade: questões contemporâneas. Nova Petrópolis, RS: Nova Harmonia, 2012. p. 11-20.

CANAVIEIRA, F. O. Por uma política para educação da primeira infância que garanta a interação entre elas: a relação criança-criança nos indicadores de qualidade na educação infantil. In: FARIA, A. L. G.; AQUINO, L. M. L. Educação infantil e PNE: questões e tensões para o século XXI. Campinas: Autores Associados, 2012. p. 31-50.

CARVALHO, R. S. O investimento na formação do cidadão do futuro: a aliança entre economia e educação infantil como estratégia da governamentalidade contemporânea. Educação em Revista, Belo Horizonte, v. 32, n. 2, p. 229-253, abr./jun. 2016. 
CARVALHO, R. S.; FOCHI, P. S. O muro serve para separar os grandes dos pequenos: narrativas para pensar uma pedagogia do cotidiano na educação infantil. Textura, Canoas, v. 18, n. 36, p. 153-170, jan./abr. 2016.

CARVALHO, R. S.; RADOMSKI, L. L. Imagens da docência com bebês: problematizando narrativas de professoras de creche. Série Estudos, Campo Grande, v. 22, n. 44, p. 41-59, jan./abr. 2017.

CONTRERAS, J. D. Pedagogías de la experiencia y la experiencia de la pedagogía. In. CONTRERAS, J. D.; FERRÉ, N. P. L. (Org.). Investigar la experiência educativa. Madrid: Morata, 2010. p. 241-271.

DAHLBERG, G.; MOSS, P.; PENCE, A. Qualidade na educação da primeira infância: perspectivas pós-modernas. Porto Alegre: Artmed, 2003.

FOCHI, P. S. Documento de orientação para estágio curricular em educação infantil. [São Leopoldo]: Universidade do Vale do Rio dos Sinos (Unisinos), 2014. p. 1-25.

FOCHI, P. S. Afinal, o que os bebês fazem no berçário? Comunicação, autonomia e saber-fazer de bebês em um contexto de vida coletiva. Porto Alegre: Penso, $2015 \mathrm{a}$.

FOCHI, P. S. Planejar para tornar visível a intenção educativa. Revista Pátio Educação Infantil, Porto Alegre, n. 45, p. 4-7, out./dez. 2015b.

FOCHI, P. S. Abordagem da documentação pedagógica na investigação praxiológica de contextos de educação infantil. 2016. 217 f. Relatório de qualificação de tese (Doutorado em Educação) - Programa de Pós-Graduação em Educação, Universidade de São Paulo, São Paulo, 2016.

FORMOSINHO, J. A formação prática de professores: da prática docente na instituição de formação à prática pedagógica nas escolas. In: CAMPOS, B. (Org.). Formação profissional de professores no ensino superior. Porto: Porto Editora, 2001. p. 46-64.

FORTUNATTI, A. Dos conteúdos às condições: por uma base ecológica de currículo. In: FORTUNATTI, A. (Org.). Por um currículo aberto ao possível: protagonismo das crianças e educação - o pensamento, as práticas e as ferramentas. San Miniato, Itália: La Bottega di Geppetto, 2016. p. 8-21.

GALARDINI, A. L. Participación. Barcelona: Octaedro, 2017.

HOYUELOS, A. La complejidad en la escuela infantil. In. HOYUELOS, A.; RIERA, M. A. Complejidad y relaciones en educación infantil. Barcelona: Octaedro, 2015. p. 13-53.

OLIVEIRA-FORMOSINHO, J. Da formação dos supervisores cooperantes à formação dos futuros professores de crianças: o ciclo da homologia formativa. 
In: GUIMARÃES, C. (Org.). Perspectivas para educação infantil. Araraquara: Junqueira G Marin Editores, 2005.

OLIVEIRA-FORMOSINHO, J. Pedagogia(s) da infância: reconstruindo uma práxis de participação. In: OLIVEIRA-FORMOSINHO, J. et al. (Org.) Pedagogia(s) da infância: dialogando com o passado, construindo o futuro. Porto Alegre: Artmed, 2007. p. 13-36.

OLIVEIRA-FORMOSINHO, J. Modelos curriculares para a educação da infância. Porto: Porto Editora, 2013.

OLIVEIRA-FORMOSINHO, J. A formação em contexto: a mediação do desenvolvimento profissional praxiológico. In: CANCIAN, V. A.; GALLINA, S. F. S.; WESCHNFELDER, N. (Org.). Pedagogias das infâncias, crianças e docências na educação infantil. Santa Maria: Ipê Amarelo, 2016. p. 87-111.

OLIVEIRA-FORMOSINHO, J.; FORMOSINHO, J. A perspectiva pedagógica da Associação Criança: a pedagogia-em-participação. In: OLIVEIRA-FORMOSINHO, J.; GAMBÔA, R. O trabalho de projeto na Pedagogia-em-Participação. Porto: Porto Editora, 2011. p. 121-143.

PARRINI, C. Ocasiões e protagonismo: o fazer e o saber das crianças no cotidiano. In: FORTUNATTI, A. (Org.). Por um currículo aberto ao possível: protagonismo das crianças e educação - o pensamento, as práticas e as ferramentas. San Miniato, Itália: La Bottega di Geppetto, 2016. p. 74-101.

RINALDI, C. Diálogos com Reggio Emilia: escutar, investigar e aprender. São Paulo: Paz e Terra, 2012.

ROCHA, E. A. C.; LESSA, J. S.; BUSS-SIMÃO, M. Pedagogia da infância: interlocuções disciplinares na pesquisa em educação. Da Investigação às Práticas, Lisboa, v. 6, n. 1, p. 31-49, jan./mar. 2016.

STACCIOLI, G. Una scuela a contracorriente: reflexión introductoria. In: RITSCHER, P. La escuela slow: la pedagogia de lo cotidiano. Barcelona: Octaedro, 2017. p. 11-22.

Rodrigo Saballa de Carvalho, doutor em Educação pela Universidade Federal do Rio Grande do Sul (UFRGS) e pós-doutor pela Universidade Federal de Pelotas (UFPEL), é professor do Programa de Pós-Graduação em Educação (PPGEDU) da UFRGS na linha de pesquisa Estudos sobre Infâncias e professor da área de Educação Infantil do Departamento de Estudos Especializados (DEE) da Faculdade de Educação dessa universidade.

rsaballa@terra.com.br 
Paulo Sergio Fochi, doutorando em Educação na linha de Didática, Teorias de Ensino e Práticas Escolares na Universidade de São Paulo (USP), é professor do curso de Pedagogia e coordenador e professor do curso de especialização em Educação Infantil na Universidade do Vale do Rio dos Sinos (Unisinos). Atua como pesquisador colaborador do grupo de pesquisa Contextos Integrados de Educação Infantil (USP, CNPq), membro da Associação Criança (Braga, Portugal), membro do Special Interest Group Birth to Three da European Early Childhood Education Research Association (EECERA) e coordenador do Observatório da Cultura Infantil (Obeci).

paulo.fochi@hotmail.com

Recebido em 29 de agosto de 2017

Aprovado em 12 de novembro de 2017 